Paukert, Craig P.; Lynch, Abigail J.; Beard, T. Douglas; Chen, Yushun; Cooke, Steven J.; Cooperman, Michael S.; Cowx, lan G.; Ibengwe, Lilian; Infante, Dana M.; Myers, Bonnie J.E.; Nguyễn, Hòa Phú; Winfield, lan J. 2017. Designing a global assessment of climate change on inland fish and fisheries: knowns and needs. Reviews in Fish Biology and Fisheries, 27 (2). 393-409. 10.1007/s11160-017-9477-y

This document is the author's final manuscript version of the journal article, incorporating any revisions agreed during the peer review process. There may be differences between this and the publisher's version. You are advised to consult the publisher's version if you wish to cite from this article.

The final publication is available at Springer via http://dx.doi.org/10.1007/s11160-017-9477-y 


\section{Designing a global assessment of climate change on inland fishes and fisheries: knowns and needs}

\section{Author affiliations and addresses}

Craig P. Paukert

7 U.S. Geological Survey Missouri Cooperative Fish and Wildlife Research Unit

8 The School of Natural Resources

9302 Anheuser-Busch Natural Resources Building

10 University of Missouri, Columbia, MO 65211

11 paukertc@missouri.edu

Abigail J. Lynch

15 U.S. Geological Survey National Climate Change and Wildlife Science Center

1612201 Sunrise Valley Drive, MS-516, Room 2A225B

17 Reston, VA 20192

18 ajlynch@usgs.gov

19

T. Douglas Beard, Jr.

21 U.S. Geological Survey National Climate Change and Wildlife Science Center 12201 Sunrise Valley Drive, MS-516, Room 2A225B

Reston, VA 20192

dbeard@usgs.gov

Yushun Chen

Institute of Hydrobiology \& State Key Laboratory of Freshwater Ecology and Biotechnology

28 Chinese Academy of Sciences

297 South Donghu Road

30 Wuhan, Hubei 430072, China

31 yushunchen@ihb.ac.cn

Steven J. Cooke

Fish Ecology and Conservation Physiology Laboratory

35 Department of Biology

36 Carleton University, 1125 Colonel By Dr.

37 Ottawa, ON, Canada, K1S 5B6

38 Steven_Cooke@carleton.ca

Michael S. Cooperman

41 Moore Center for Sciences

42 Conservation International

432011 Crystal Dr., Suite 500

44 Arlington, VA 22202 USA

45 mcooperman@conservation.org

Ian G. Cowx

48 Hull International Fisheries Institute

49 University of Hull, Hull HU6 7RX, UK

$50 \quad$ I.G.Cowx@hull.ac.uk

Lilian Ibengwe

Ministry of Agriculture, Livestock and Fisheries

56 Dar es Salaam, Tanzania 
lilyibegwe@gmail.com

Dana M. Infante

60 Department of Fisheries and Wildlife

61 Michigan State University

62 Manly Miles Building, Suite 318

631405 South Harrison Road

64 East Lansing, MI 48823

65 infanted@msu.edu

Bonnie J. E. Myers

68 U.S. Geological Survey National Climate Change and Wildlife Science Center

12201 Sunrise Valley Drive, MS-516, Room 2A225B

Reston, VA 20192

bjmyers@usgs.gov

Nguyễn Phú Hòa

Nong Lam University - Ho Chi Minh City

Ho Chi Minh City, Viet Nam

phuhoa@hcmuaf.edu.vn

Ian J. Winfield

Lake Ecosystems Group, Centre for Ecology \& Hydrology,

Lancaster Environment Centre, Library Avenue

Bailrigg, Lancaster, Lancashire LA1 4AP, U.K.

ijw@ceh.ac.uk

Authors are listed alphabetically after the first two authors.

\begin{abstract}
(150-250 words)
To date, there are few comprehensive assessments of how climate change affects inland finfish, fisheries, and aquaculture at a global scale, but one is necessary to identify research needs and commonalities across regions and to help guide decision making and funding priorities. Broadly, the consequences of climate change on inland fishes will impact global food security, the livelihoods of people who depend on inland capture and recreational fisheries. However, understanding how climate change will affect inland fishes and fisheries has lagged behind marine assessments. Building from a North American inland fish assessment, we convened an expert panel from seven countries to provide a first-step to a framework for determining how to approach an assessment of how climate change may affect inland fishes, capture fisheries, and aquaculture globally. Starting with the small group helped frame the key questions (e.g., who is the audience? What is the best approach and spatial scale?). Data gaps identified by the group include: the tolerances of inland fisheries to changes in temperature, stream flows, salinity, and other environmental factors linked to climate change, and the adaptive capacity of fishes and fisheries to adjust to these changes. These questions are difficult to address, but long-term and large-scale datasets are becoming more readily available as a means to test hypotheses related to climate change. We hope this perspective will help researchers and decision makers identify research priorities and provide a framework to help sustain inland fish populations and fisheries for the diversity of users around the globe.
\end{abstract}

Key words: 4-6 key words climate change, freshwater, inland, livelihoods, food security, recreational fishing 


\section{Introduction}

There are few syntheses of how climate change may affect inland fishes and fisheries (defined as those found in lakes, rivers, streams, canals, reservoirs, and other land-locked waters including diadromous species; FAO 2014a) at a global scale. A recent review of how inland fishes and fisheries are impacted by climate change in the U.S. and Canada was conducted (Hunt et al. 2016; Paukert et al. 2016a; Whitney et al. 2016; Lynch et al. 2016b) but these issues focused on maintaining biodiversity and recreational fishing, and not on many of the pressing issues for developing countries and other regions. Conversely, many fisheries are often focused on food security with limited recreational fisheries, and/or limited assessment or accurate reporting (Cooke et al. 2016a).

Inland fishes and capture fisheries and aquaculture are an important component of global fish production. They accounted for over 35\% of reported global fisheries production in 2014 (FAO 2016) and potentially account for over $40 \%$ of global production when just considering finfish (Lynch et al. 2016a). While climate change will substantially affect both freshwater and marine systems (IPCC 2014), many assessments of fishes responses to climate change focus on marine or estuarine fishes (e.g., Roessig et al. 2004). Much of the climate change work for inland fishes has focused on species-specific responses (e.g., Kovach et al. 2016), or on developed countries ( e.g., Whitney et al. 2016; Lynch et al. 2016b) with little research on inland waters in Mediterranean and tropical biomes (Comte et al. 2013). It is uncertain how lessons learned from these efforts on freshwater community responses to climate change would transfer to a broader geographic scope, including the developing nations of the tropics. At a minimum, such an effort at scaling up would require identification of the different management priorities and value driving the need for sustainable inland fisheries (Cooke et al. 2016a). However, a global assessment is likely to need a diversity of approaches (for fish and fisheries), with specific approaches tailored to the geographic region and sector of interest. Nevertheless, certain broadly applicable generalities likely exist when assessing how inland fisheries are likely to respond to climate change.

An expert panel workshop was convened to provide a first-step to define a framework for how to approach the very challenging task of an assessment of how climate change may affect inland fishes, capture fisheries, and aquaculture. Our intention was not to identify a specific process that would encompass all the values and sectors on inland fishes, fisheries, and aquaculture, but to identify common concerns and themes across sectors and regions. In North America and other industrialized countries, maintaining biodiversity and recreational fishing are the primary drivers for fisheries management and conservation (Hunt et al. 2016); however, in other regions, food security and human livelihoods are the major factors driving the need for sustainable inland fisheries (Cooke et al. 2016b). Therefore, our panel had expertise on sustainable fisheries in various regions of the world, fish population dynamics, recreational fisheries, biodiversity, and climate change.

Assessing how climate change may affect inland fishes, capture fisheries, and aquaculture is a very complex issue with multiple facets. The group identified three themes that broadly encompass the most important values of inland fisheries on a global scale: food security, livelihoods, and recreational fishing. Other values that are embedded in these three themes are important when considering the effect of climate change on inland fishes and fisheries. For example, cultural norms may determine who is allowed to fish in a village and thus may affect the livelihoods of fishers (Coulthard 2008). If fish abundance declines due to climate change, villagers that are not allowed to fish may be more resilient to climate change than fishers whose livelihoods depend on sustainable fisheries. Changes in climate may be pathways for increased fish contaminants through temperature-contaminants interactions (Noyes et al. 2009), which may in turn affect food security. Our perspective seeks to identify an organizational approach for conducting a critical evaluation of existing literature and expert option (i.e., an assessment) of climate change impacts on inland fishes, fisheries, and aquaculture so we can identify data gaps and research needs, as well as commonalities and differences across regions or sections so policy makers can learn from others with similar concerns. The ultimate goal of this process is to help agencies and organizations prioritize actions and funding to ensure sustainable inland fisheries resources through adaptive management in the face of a changing climate. Our approach is built around three broad themes of food security, livelihoods, and recreational fishing.

\section{Food security}

Food security is among the greatest global concerns (Godfray et al. 2010). Globally, over 4.5 billion people rely on fishes for at least $15 \%$ of their average animal protein intake (Béné et al. 2015). Low-income food-deficit countries account for $80 \%$ of the total reported harvest from inland capture fisheries (Kapetsky 2003) with 90\% of inland capture fisheries used for human consumption (Welcomme et al. 2010). In Bangladesh and Cambodia, inland fisheries account for approximately $60 \%$ and $79 \%$ of animal protein consumed, respectively (Belton and Thilsted 2014). If a region relies heavily on one food source (e.g., fish, livestock, rice), it is vulnerable to food insecurity as threats to that particular food source arise (e.g., climate change, human land use) potentially increasing the number 
of people at risk of hunger (Schmidhuber and Tubiello 2007). In Africa, one-third (2.7 million tonnes) of total capture fisheries production comes from inland waters (FAO 2014b). Tanzania is one of the greatest inland fisheries nations in Africa, ranking in the top ten countries of the world for inland capture fisheries (FAO 2014b). The country shares three great lakes (Victoria, Tanganyika, and Nyasa/Malawi/Niassa) and supports numerous people by providing fishes for their protein, employment, income, foreign earnings, and revenue to the country (FAO 2007). Therefore, the risk of food insecurity for those who rely upon fisheries is significant.

As global change impacts inland fisheries worldwide, human populations, especially in developing countries, may be increasingly threatened by food insecurity (Marx 2015). Increasing temperatures, change sin streamflow patterns, and salinity intrusion will affect inland fisheries and aquaculture, but the effects may vary across regions and species. Climate change may affect species composition, production, yield, and distribution, as well as drive prevalence of diseases and colonization of invasive species. Climate change may have some positive effects as warmer temperatures and growing seasons may increase fish production for both capture fisheries and aquaculture (Bander 2007); however, if a fish's thermal optimum is exceeded, it may be more susceptible to decreased cardiorespiratory performance, compromised immune function, and altered patterns of individual reproductive investment (Whitney et al. 2016).

These impacts have already affected some of the important inland water bodies with substantial fisheries. In Lake Victoria, about $85 \%$ of the water entering the lake comes from precipitation with the remainder from rivers, and rising temperatures and changing precipitation patterns have resulted in fluctuating water levels, which, along with other stressors including hydropower, lead to destruction of breeding grounds in shallow waters, alteration of fish life cycles, changes in size of fish populations, and changes in biodiversity. Other African great lakes are also likely impacted, but how they may be affected remains unclear. Seasonal monsoon patterns may change, and the consequences of that change, such as altered mixing and stratification, is currently unclear (MacIntyre 2012), but might affect primary productivity, fish spawning periods, success of larvae, and the overall fish production in the region (FAO 2010). Fish nursery areas may also be affected as inshore vegetation, which supports high fish diversity, transitions to exposed, dry, and rocky habitats which tend to be far less productive. Understanding how climate change affects African great lakes and other systems fisheries, ecology, fish production, and the local communities is needed to understand impacts on food security.

\section{Livelihoods}

Inland fisheries contribute greatly to livelihoods by providing income generation, employment, and, in cases where other employment opportunities are lost, a safety net or fallback option (Smith et al. 2005; Welcomme et al. 2010; Youn et al. 2014). Employment can be from fishing-related activities, such as fish processing and selling. The Food and Agriculture Organization of the United Nations (FAO) estimates there are 4.5 million fishers worldwide, and women comprise an estimated 54\% of the workforce (Welcomme et al. 2010); however, this number is considered a gross underestimation considering other estimates of inland fishers in just eight countries in Southeast Asia (Indonesia, Malaysia, Myanmar, Philippines, Thailand, Cambodia, and Vietnam) exceeds this global FAO metric (Coates 2002; Béné et al. 2003).

Inland fisheries' livelihoods are important around the world. In the Lower Mekong River Basin, inland fishes and fisheries are a critical component of the economy and culture with 4.4 million tonnes from capture fisheries and aquaculture production totaling an estimated value of $\$ 17$ billion per year (Nam et al. 2015). In particular, the Mekong River delta is the most productive area for aquaculture and fisheries in Viet Nam (Wilder and Nguyen 2002). For example, striped catfish Pangasianodon hypophthalmus production has now exceeded 1 million tonnes with a value of over US\$ 2 billion and supports the livelihoods of 180,000 to 200,000 people (Halls and Johns 2013). In China, inland fisheries have a net worth of more than 550 billion Chinese Yuan from freshwater aquaculture and commercial fishing (about \$US83 billion annually; MOA 2015) and support about 10 million people (MOA 2015). In the Lower Mississippi River Basin of the United States, the catfish industry processed 136,500 tonnes in 2014 with most production in southern states such as Alabama, Mississippi, Arkansas, and Louisiana (Hanson and Sites 2015). Therefore, inland fishes and fisheries contribute substantially to the livelihoods of many people and cultures, and thus the effects of climate change on fishes and fisheries are a critical employment concern.

Climate change impacts stemming from altered temperature and precipitation patterns may directly and indirectly affect livelihoods by changes in fish production, growth, survival, availability and diversity (Cochrane et al. 2009; Chen et al. 2016). Ninety percent of inland fisheries occur in Africa and Asia (Cochrane et al. 2009), where temperature increases are expected to exceed the global annual mean warming (Christensen et al. 2007). In China, ponds and lakes, where a majority of inland fisheries occur, may be strongly affected by climate change, especially drought and warming (Yu 2009; Yang et al. 2016), and models that incorporate precipitation in the driest month, 
temperature annual range, and annual mean temperature can be used to predict fish assemblages in Chinese lakes (Guo et al. 2015). In Viet Nam, river flows upstream of the Mekong River delta in the dry season 2015-2016 were at historic lows due to an El Nino year, and these events are projected to become more frequent and stronger (Kiem et al. 2008). Likewise, sea level rises (coupled with decreasing sediment supply to the Mekong River delta stemming from trapping at upstream hydropower impoundments) have also caused an influx of salt water into main channels (P. Hoa, unpublished data). Therefore, neglecting to recognize the important contributions of inland fisheries to livelihoods in light of climate change, will increase the difficulty in supporting those livelihoods, especially in rural communities (FAO 2014b; Cooke et al. 2016a).

\section{Recreational fishing}

Recreational fishing, defined as fishing without the primary objective of subsistence or commercial trade (FAO 2012), is a popular activity around the globe (Cooke and Cowx 2004). On most industrialized continents such as Europe, North America, and Australia, recreational fisheries represent the primary fisheries sector in inland waters (Arlinghaus et al. 2002; FAO 2012). Inland fishes and recreational fisheries in the United States (U.S.) contribute over \$US26 billion annually, making them a very important part of the U.S. economy (USFWS - USCB 2011). Recreational fisheries provide substantial additional value because they can also boost other tourism industries (reviewed in Cooke et al. 2016a). For example, recreational fisheries substantially increased revenue for dining and lodging services in China (Yu 2009; Yang et al. 2016). Even in emerging economies, inland recreational fisheries are expanding due to angling tourism and increasing domestic participation (e.g., Brazil: Freire et al. 2012; India: Gupta et al. 2015). In some jurisdictions, recreational fisheries are intensively managed based on stock enhancement programs to achieve diverse objectives such as creation of trophy fisheries or to provide harvestable fishes within a target size range (FAO 2012; Cooke et al. 2016a).

For these intensively managed recreational fisheries, climate change has the potential to alter the ability of managers to achieve their objectives (Paukert et al. 2016a). Climate change impacts fish physiology (Whitney et al. 2016), populations and communities (Lynch et al. 2016b), and the decisions of recreational anglers (Hunt et al. 2016). These changes are often linked to changes in water temperature and stream flows, causing drought and increased salinity from saltwater intrusions in some inland systems. However, even in developed countries such as the U.S. and Canada, there are few documented cases of how climate change affects inland fishes; those that do exist primarily link to distribution and phenology (Lynch et al. 2016b). In developing countries where there is less management capacity targeted towards the recreational sector, the potential consequences are difficult to predict. In addition, there is also little research on how climate change may affect the recreational fishers through changes to fishes and fish habitats, changes to fishing opportunities (e.g., increased air temperature reducing ice cover at northern latitudes, which will extend the open-water fishing season and effort), and changes in government mitigation and adaption strategies (e.g., energy policies that may increase fuel prices so fishing trips are more expensive; Hunt et al. 2016). What is clear is that the recreational sector active in inland waters will have to adapt in the face of global change. What that adaptation will look like requires knowledge of how inland waters around the globe will be altered by climate change and progressive thinking about how recreational fisheries can adapt to continue to provide maximum benefits to anglers and more broadly to society.

\section{Structuring a global assessment \\ Need}

To address the need for a global assessment of climate change on inland fishes and fisheries, we convened a scoping meeting of experts from around the world to discuss the needs, challenges, and future research directions with the objective of developing a framework for assessing climate change effects on inland fishes and fisheries at a global scale. We followed a similar approach to a recent North American assessment on the effects of climate change on inland fisheries (see Paukert et al. 2016b). We invited participants from seven countries representing academics and agency personnel. This team was selected based on reputation and publication record in inland fisheries assessment and/or climate change and met on 21 May 2016 in Busan, South Korea. Our goal was to have an initial small meeting to determine the feasibility of a global assessment and make recommendations if we identified a viable approach forward. Some of the questions we wanted the group to answer were:

- What is the biggest challenge to developing a global inland fisheries assessment?

- What are the best approaches to determine an assessment?

- What are the research needs to achieve a comprehensive assessment?

The potential effects of climate change on inland fishes, fisheries, and aquaculture do not just affect inland fishes themselves but upscale through the food and market chains to food security, livelihoods, and recreational 
fisheries. Consequently, these issues need to be integrated into local, national, regional, and global development initiatives and debates relating to food security, such as those embedded in the Sustainable Development Goals (UN 2016). There is, thus, a clear mandate to raise the importance and value of inland fishes and fisheries in the political arena (in terms of contribution to livelihoods and social and economic perspectives) (Cooke et al. 2013; Cooke et al. 2016a), and the conservation and recreational services they deliver (Cowx et al. 2010). It is also critical to predict and anticipate the nature and magnitude of potential impacts of climate change on food production and recreational services. Working with the industries concerned is necessary to develop innovative adaptation and mitigation strategies to enhance resilience to perceived threats, and to facilitate access to opportunities (e.g., the 'blue-growth' agenda).

To achieve this, there is a need to engage with other aquatic resource and food production sectors and the public at large, and understand the motives and drivers of these sectors in an effort to optimize use of what could be potentially limiting water resources in the future (Cooke et al. 2013). It is important that inland fishes and fisheries are represented in river basin planning and management, and included in the emerging scientific dialogue around concepts, such as ecosystem services (Table 1) and ecosystem-based management (Beard et al. 2011; Cowx and Portocarrero Aya 2011), to maintaining the functional ecosystems for fisheries (Brummett et al. 2013).

With the expert panel, we discussed and suggested the following considerations of scale, approach, and challenges for a global assessment:

\section{Scale}

Climate change is a global phenomenon, and Intergovernmental Panel on Climate Change (IPCC) predictions (2014) suggest changes in precipitation and temperature around the world. However, consequent effects on fishes and fisheries are influenced by localized landscape factors, such as elevational gradients, coastal effects, large inland water bodies, and rain shadows, resulting in regional climate patterns (Daly 2006; Wiens and Bachelet 2010). Ecoregions encompass areas of the landscape, including freshwater habitats, with geographically distinct assemblages of species and broadly similar environmental factors such as geology, vegetation, and regional climate (Abell et al. 2008). Regional downscaling models provide valuable insights into the predicted meteorological changes but translating these into impacts on aquatic ecosystems, and ultimately fishes and fisheries, is fraught with uncertainty at each step in the modelling process. The main problem is that individual watersheds have specific hydrologic and ecosystem characteristics and these function in different ways. Additionally, other competing uses for water make any direct linkages to fish response more complex.

Consequently, to determine any likely impact on inland fishes and fisheries, there is a need to define the scale over which any assessment is undertaken. This needs to be feasible in terms of a knowledge base of ecosystem biodiversity and functioning of the target system, but also appropriate in terms of the uncertainty associated with climate downscaling models to provide defensible predictions. In addition, the availability of biological data is highly variable globally. At the scale of individual watersheds, states, provinces, and occasionally entire countries, comprehensive species inventories exist and biological data sets may also be available. Yet, many regions, particularly in developing countries and the tropics, lack such information (Williams 1996; Dudgeon et al. 2006; Darwall et al. 2008). Where regional datasets exist, their harmonization into comparable formats requires major investments to support the entities organizing the information as well as cooperation from the data providers (Midway et al. 2016; Whittier et al. 2016). The use of these datasets for any future assessments requires a spatial framework that distinguishes water bodies in a common manner (e.g., National River Spatial Dataset; Wang et al. 2016). For global assessment, such a spatial framework should span political boundaries within continents and ensure characterization of all fresh waters of interest.

Working at the regional scale will likely be inaccurate from the ecosystem perspective because of the high potential diversity between river basins across single regions, whereas working at the individual river basin scale will be impractical. We therefore suggest to undertake any assessment at the freshwater ecoregion level (e.g., Abell et al. 2008; http://www.feow.org/globalmap; Orians 1993; Olson and Folke 2001). Such ecoregions are well defined in freshwater conservation management and account for differences in fish distributions based on evolutionary history and ecological boundaries. In addition, species responses to changing climate may vary by region (Paukert et al. 2016b), and climate scenarios developed for ecoregions must capture those variables that will lead most directly to changes in water temperature, precipitation, and phenology associated with regional fishes of interest (e.g., Sievert et al. 2016). There may be problems, however, arising within large river basins, such as the Mekong, where the river is broken down into several ecoregions where each can potentially influence those upstream and downstream in the watershed, especially where long-distance migrating fishes contribute significantly to the fisheries. Consequently, under these circumstances, it may be necessary to combine or relate ecoregions to 
understand the full impacts of climate change on the hydrologic and limnologic characteristics and associated effects on inland fishes and fisheries.

\section{Approach}

Climate change sciences are fraught with uncertainty, even more so when translating into impacts on aquatic ecosystems. Many empirical models have been developed to assess the impact of climate change on ecosystems and biota, but many are based on direct relationships between temperature and hydrologic variables and rarely account for uncertainty or adaptation to changing conditions. They also do not explore the exposure of fisheries and aquaculture to climate change effects or consider the sensitivity of these sectors to climate and other elements of global change, thus indicating the scale of the potential problem.

For a global assessment of climate change impacts on inland fishes and fisheries, we recommend utilizing an emerging approach, risk and vulnerability assessments, where the vulnerability to a hazard (i.e., climate change) is broken down into exposure, sensitivity, and adaptive capacity (Foden et al. 2013). The principal advantage of these assessments is that they can incorporate both qualitative and quantitative knowledge. Such assessments originate in work by the IPCC (2001) and have been applied to marine fisheries globally (Cheung et al. 2013; Cheung et al. 2016). As a first step, a series of stakeholder-informed conceptual models are needed exploring how the main components of risk (assessment and management) from climate change impact the inland fisheries sector (commercial, subsistence, and recreational). These should analyze: (i) the threats or change likely to cause a specific event (e.g., losses or change in a particularly fishery) as well as (ii) prevention measures limiting the severity of the event, then identify (iii) the consequences of the event occurring, and (iv) mitigation measures that can minimizing those consequences. Cause-effect (consequence) tools such as the Eco-evidence (http://www.toolkit.net.au/tools/eco-evidence) or Bowtie tools (Cromier et al. 2013), can be used to support this assessment.

Such assessment requires engagement with all stakeholders to determine the likely impacts and consequences to food security and livelihoods. This will require inputs from a wide range of end users (e.g., fishers, fishing communities, policy makers) and incorporate both data-rich and data-poor scenarios, coupled with expert opinion. Embedded within this framework should be vulnerability assessment of species, populations, communities, ecosystems, and the people dependent on the fisheries resources.

\section{Identified challenges to a climate change and inland fishes assessment}

Physiological and population data are essential for identifying inland fishes and fisheries vulnerable to changes in climate to facilitate their conservation and management (Paukert et al. 2016b), and to aid in managing expectations and needs of people who depend on fisheries resources (Paukert et al. 2016a). Fisheries census data over large spatial extents are critical for first identifying habitats supporting species threatened by current stressors, such as anthropogenic land use and overfishing, and for identifying those habitats that are vulnerable based on their ability to support species with changes in climate. More detailed biological data, including information on population size structure, growth rates, and life histories, are also necessary for conducting regional analyses to elucidate associations between fishes and key climate drivers so that results can be extrapolated to similar habitats that may lack such information.

Data necessary for a global assessment of inland waters should include information characterizing distributions of species throughout rivers, lakes, and wetlands, with preferable data sets including those that characterize species abundances and assemblage compositions to understand overall community dynamics. Also important are datasets which characterize physiological constraints of individual species, which may be the ultimate drivers of changes in assemblage composition that would occur with changes in climate (see Wikelski and Cooke 2006; Pörtner and Farrell 2008; Whitney et al. 2016). Such understanding, coupled with large-scale inventories of species distributions, can be used to anticipate range shifts and novel species interactions that may occur with climate-induced changes in habitats (e.g., temperature, hydrology, water quality; Comte and Grenouillet 2013; Whitney et al. 2016). Efforts to prioritize the acquisition of biological data for global assessment should target data from a diversity of inland water bodies globally, including ecologically unique habitats occurring across a broad range of climactic conditions, as well as data from habitats supporting culturally and economically important fisheries.

Fresh water is a shared resource. Water challenges (i.e., too much, too little, too dirty) are recognized to have global implications. Many sectors rely upon water and, in some cases, the limited availability of water leads to tough decisions. Though inland fishes and fisheries play important roles in providing food security, human wellbeing, and ecosystem productivity, this sector is often underappreciated in water resource planning because valuation is difficult and governance is complex, unclear, or non-existent (Lynch et al. 2016a). Additionally, inland 
fisheries are an economically small sector and, in most cases, the value of inland fisheries will never be the main driver of decision making. Management of sustainable inland water systems requires making informed choices emphasizing those services that will provide sustainable benefits for humans while maintaining well-functioning ecological systems (Cooke et al. 2016a).

\section{Future directions}

\section{Identified research needs}

Our expert panel developed a list of priority research needs for inland fishes, fisheries, and aquaculture related to climate change. These ratings were separated by theme (food security, livelihoods, and recreational fishing) as each theme may have different priorities. The expert panel was then asked to identify priority research needs. The group, by consensus, selected 13 different needs within five categories: thermal or flow tolerances, fish population responses, fishers and other users (e.g., fish farmers), production, and geographic scope. Each expert was asked to rank each of the 13 priority needs as low (1) medium (2) or high (3) for each theme (Figure 1).

Several patterns emerged from this exercise. The most important information needs for food security were related to fishers and other users, and fish population responses to climate change (mean rank >2.4). In general, how users of fishes will respond to drought and how fishing communities may cope with changes in fish production and how fish population size may change with climate were priority needs for food security. In contrast to other themes, fish responses to thermal and hydrologic regimes (mean rank <2.4) were not important for food security.

Understanding fisher response to climate was a high priority need for livelihoods (mean rank >2.6), followed closely by how fish production may respond to climate. More specifically, understanding how saltwater intrusion (in coastal areas) may affect production systems was important for livelihoods. In general, fish tolerances to thermal and hydrologic regimes were relatively low priority (mean rank of 2.0 to 2.4), although understanding the adaptive capacity of fishes to respond to these changes in hydrology and temperature was the greatest need in the thermal/flow responses category for livelihoods (mean rank of 2.6).

The priority needs for recreational fisheries differed markedly from the livelihoods and food security themes with regards to thermal and flow tolerances and fish production. Priority needs related to thermal and flow tolerances of fishes were typically ranked high for recreational fisheries (mean rank of 2.6 to 2.8). However, fish population responses were also ranked high for this theme (mean rank of 2.4 to 2.6). Quantifying the linkage between production, floodplains, and climate, and understanding how saltwater intrusion may affect fish production or impact recreational fishing were ranked the lowest of any data gap (mean rank of 1.1 to 1.5).

Across all themes, our expert panel identified a need to have better geographic representation in research, regardless of data gaps (Figure 1). Below, we expand on several high priority research themes identified in Figure 1: adaptive capacity, dynamic energy and temperature budgets, environmental variables (beyond temperature), and large datasets.

\section{Account for adaptive capacity}

A relatively consistent priority need was to understand a fish's adaptive capacity to respond to thermal and hydrologic changes. Quantifying the ability of inland fishes to adapt to novel environmental conditions will be an essential component to any assessment of how inland fisheries will respond to climate change (Huey et al. 2012; Foden et al. 2013). However, research into the adaptive capacity of inland fishes to changing environmental conditions has lagged well behind that for terrestrial and marine organisms (Heino et al. 2009). Although inland fishes may have the ability to adapt to changing hydrology and temperature conditions (Eliason et al. 2011), we have little information on some of the most basic metrics such as maximum thermal and flow tolerances. This basic information is often limited for many economically and socially valuable species, and can be nonexistent for other species because of their lack of perceived value and conservation significance. For example, even in a relatively small region like the state of Missouri, U.S., at least $25 \%$ of the wadeable stream fish species are lacking thermal or flow tolerances data (Sievert et al. 2016).

However, there is also a compelling need for research to address the demographic consequences of changing environmental conditions. For example, while research has addressed the capacity for acclimation to upper thermal tolerance limits (i.e., Critical Thermal Maximum; CTmax) in response to warming temperatures within fishes, these studies typically occurred over short time spans (i.e., weeks) and involved relatively rapid changes in temperature (Peck et al. 2009). In addition, much of the current body of work on climate change impacts on fishes is that experimental exposure levels tend to be stable (e.g., temperatures held at $25^{\circ} \mathrm{C}$ for 3 months), which may fail to reflect the reality experienced in the wild where temperature can vary even on a diel basis or over fine spatial scales 
and therefore it is challenging to extrapolate results to the long-term creep of climate change. Nevertheless, these Unfortunately, these experiments typically fall short of making a mechanistic linkage between measured variables, such as temperature, specific oxygen consumption rates (a proxy for scope for aerobic activity), and demographic responses such changes in age specific growth rate, fecundity, or gamete quantity or quality. Failure to use realistic thermal scenarios that incorporate diel and seasonal heterogeneity (see Terblanche et al. 2007; Terblanche et al. 2011; Huey et al. 2012), changes in phenology, and also simulate extreme events (e.g., Donaldson et al. 2008 for cold shock) will limit our ability to predict the consequences of climate change on inland fishes. As such, these represent significant research priorities.

Accurately quantifying capacity for adaptation to new conditions is only a part of the knowledge base needed for assessing how inland fish species will respond to climate change. For example, Stillman (2003) identified how close an organism's upper thermal tolerance limit is to existing high temperatures as a critical consideration of thermal adaptation ability and its vulnerability to warming temperatures. Therefore, a detailed knowledge of current temperature norms and organismal upper tolerance levels would be essential to assessments of vulnerability and adaptive capacity. Thermal tolerances and physiological adaptation vary depending on whether animals are provided with stable or dynamic temperatures (Beitinger and Bennett 1999; Beitinger et al. 2000; Angilletta 2009).

Further complicating matters is the growing body of evidence that individual-based differences within populations combined with the potential presence of population-specific local adaptation to prevailing conditions may render extrapolation of limited empirical datasets to broad generalizations suspect (Newton et al. 2010; Norin et al. 2016). Vulnerability of species to climate change is often linked to life history traits (e.g., Chessman 2013; Sievert et al. 2016). Given that we cannot measure adaptive capacity of every individual or fish species, measuring these metrics for different thermal guilds may be a suitable alternative (e.g., Comte and Grenouillet 2013).

Therefore, a generalization in any assessment of the climate change impact on inland fisheries is a challenge given the dichotomy in the adaptive capacity between temperate and tropical species, with tropical species likely more susceptible to deleterious impacts because of narrower thermal tolerances (Janzen 1967; Deutsch et al. 2008).

\section{Model dynamic temperature / energy budgets}

Understanding the energy budgets of fishes is a critical step to determine how inland fisheries respond to climate. For inland fisheries, water temperature is the 'master factor' governing energy-demanding metabolic processes (Brett 1971), in addition to distribution and dispersal of individuals. Therefore, climate-change induced alteration to the thermal characteristics of inland waters will presumably affect the ways in which fishes obtain, allocate, and expend energy (reviewed in Whitney et al. 2016), influencing individual fitness and population productivity (Rijnsdorp et al. 2009; Pörtner and Peck 2010). Fish energetics have been studied for decades (Brett and Groves 1979; Tytler and Calow 1985), leading to the development of a number of bioenergetics modeling approaches (Ney 1993; Petersen and Paukert 2005) and species-specific bioenergetics models (e.g., Kitchell et al. 1977; Rice and Cochran 1984). Contemporary bioenergetics modeling approaches, such as "dynamic energy budgets" (DEB), provide opportunities for exploring climate change impacts on fisheries because they can be integrated with individual-based models for predicting climate change impacts (Martin et al. 2012; see Freitas et al. 2010 for a marine fish example).

\section{Expand beyond temperature}

Fisheries response to increasing temperatures in inland habitats has been the focus of the majority of climate change and inland fisheries studies to date on fish phenological, demographic, and distributional changes, particularly in coldwater fishes (e.g., salmonids; Comte et al. 2013; Lynch et al. 2016b). In addition to increasing temperatures, climate change can alter drought duration, flow variability, and precipitation patterns, which also influence fish populations (Krabbenhoft et al. 2014; Ward et al. 2015) and may be coupled with the emergence of "no-analog" communities (Huey et al. 2012; Urban et al. 2012). Although climate-induced changes in stream flow have been a commonly studied to determine climate change effects on trout (Oncorhynchus and Salmo species) globally, many other species, other climate change mechanisms, and geographic regions are not well represented in the literature (Kovach et al. 2016).

In North America, only five documented studies identified between 1985 and 2015 focused on climate variables other than temperature (e.g., precipitation, flow variability, and ice cover) to assess climate change effects on inland fisheries (Lynch et al. 2016b). There is also a paucity of information on the potential complex and variable fisheries responses to climate change, including fish community structure, susceptibility of fishes to diseases, and novel interactions among species (Lynch et al. 2016b). Similarly, only two studies on North American inland 
fisheries examined changes to fish diversity and species interactions in response to climate change (Moore et al. 1995; Muhlfeld et al. 2014).

Recent climate and inland fishes syntheses revealed biases towards certain geographic areas, such as the Northern Hemisphere and temperate regions, and a lack of information for most of the globe, especially high needs areas, such as Asia and Africa (Cochrane et al. 2009; Comte et al. 2013; Kovach et al. 2016). Much is still unknown in terms of the complex and nuanced ways in which fisheries may respond to climate change globally and the effects of lesser studied climate variables on inland fishes and fisheries. Therefore, a need exists to further augment our understanding of climate change effects on inland fishes and fisheries to expand beyond studying temperature effects on fish distributions, phenology, and growth to including other relevant climate variables and potential fisheries responses at more geographically representative scales globally.

\section{Build from existing, long-term datasets}

Understanding the effects of climate change on inland fishes and fisheries benefits greatly from the use of long-term data sets (where available). The value of long-term datasets has been long appreciated. Over 25 years ago, Elliott (1990) remarked on their value for both fundamental and applied freshwater studies and noted the low statistical power of short-term studies to detect subtle effects arising from a range of environmental problems including climate change. Elliott (1990) indicated that long-term studies require very substantial commitments of funding, staffing, and facilities and there is always a danger that long-term investigations may fall into unproductive complacency, for which the appropriate remedy is regular scrutiny and analysis. These characteristics persist to the present day in which lake and other inland aquatic ecosystems have become more complex as a result of a range of interacting multiple stressors including climate change, eutrophication, and species introductions (Maberly and Elliott 2012).

However, long-term monitoring is a critical element to understand fishes and fisheries responses to climate change (Paukert et al. 2016a). In the U.S., the Long Term Ecological Research Network (www.lternet.edu) was created in 1980 with the specific remit to conduct research at the temporal scale of decades and the spatial scale of large geographical areas. This far-sighted initiative was followed in 1993 by the founding of the International Longterm Ecological Research Network (www.ilternet.ceh.ac.uk) which consists of networks of scientists from around the world, including the Long Term Ecological Research Network, engaged in long-term, site-based, ecological and socioeconomic research. Although the outputs of these networks have been diverse and voluminous, as recently illustrated by Maass and Equihua (2015), a detailed inspection (see listings within the above websites) reveals that inland fishes and fisheries feature infrequently (e.g., Comte and Grenouillet 2013).

An effective and efficient global assessment of climate change impacts on inland fishes and fisheries requires, with some urgency, that we build from these existing largely non-fish datasets and add extensive fish datasets held by a range of fishes and fisheries researchers and managers around the world. Some of these combined datasets already occur but vary by region. In Europe, standardized reporting is required by countries held to the European Union Water Framework Directive (http://ec.europa.eu/environment/water/waterframework/info/intro_en.htm), a stream fish diversity and biomass dataset is available from thousands of locations across the European Union (Logez et al. 2013), and a corresponding but smaller dataset has recently been provided for lakes (Mehner et al. 2017). In the U.S., stream fish abundances from across the contiguous U.S. have been compiled in support of the National Fish Habitat Partnership; these data were voluntarily provided by state and federal programs and synthesized into a comprehensive and comparable data layer for use in a current condition assessment of fish habitats (http://assessment.fishhabitat.org/). At a global scale, the Global Freshwater Biodiversity Atlas (http://atlas.freshwaterbiodiversity.eu/) is an unprecedented effort to conduct a global accounting of fishes and other taxa supported by freshwaters. The atlas includes maps and data sources of varying resolutions providing spatial characterizations of fishes and other aquatic organisms globally. These and other large-scale data sets can serve as sources of data as well as models for development of integrated data sets for assessing fish response to climate change. However, there is still a strong need for datasets from other regions of the world. In addition, there is a need to collect these new data wherever possible using standard methods (Bonar et al. 2017).

\section{Conclusions}

Several opportunities and research needs were identified throughout the workshop process. Our expert panel included many researchers who, not surprisingly, agreed that more research is needed. Incorporating other stakeholders that include more decisions makers and information users in subsequent steps of an assessment will help couch the research priorities with decision makers that may have better understanding of funding mechanisms for the research, or how to best leverage limited resources to achieve the greatest effect, such as using existing data to answer questions related to climate change. 
We have more opportunities now because of the substantial amount of existing, long-term datasets available, such as the International Long Term Ecological Research Network. However, we still have challenges to determine the energy budgets of fishes, particularly under dynamic temperature regimes, and the adaptive capacity of these fishes to potentially absorb these climate-driven changes. Coupling these concerns with the lack of understanding on how abiotic factors other than temperature may affect fishes (Staudt et al. 2013), how climate change may affect fishes through the food web and other pathways (Lynch et al. 2016), the response of the human users (e.g., Hunt et al. 2016), and how these responses may differ among regions indicates we need more information to help governing bodies and users of inland fishes better adapt to climate change.

Our expert panel concluded that an assessment of the effects of climate change on inland fishes and fisheries at a global scale will be challenging because of the diversity of inland fishery resources and varied regional uses worldwide, coupled with the diversity of inland fisheries and their differential responses to climate change. In addition, the broad themes of food security, livelihood, and recreational fishing encompass multiple sub-themes such as the importance of cultural or societal norms related to fisher livelihoods, or how contaminant-temperature interactions may affect fishes and thus food security and human health. However, identifying key issues relating to climate change and inland fishes, fisheries, and aquaculture is a critical step to help researchers and management agencies understand the potential impacts of climate change and will guide future research and the development of adaptation strategies in the face of climate change. Our approach, starting with a small team of experts, to this large and complex problem can help guide efforts that may initially seem overwhelming or too challenging.

Many large-scale assessments of climate change involve modeling future trends of various metrics (e.g., Lobell et al. 2008; Bellard et al. 2012), or have addressed specific regions like the U.S. (Grimm et al. 2013) or, slightly more broadly, North America (Paukert et al. 2016b). Our proposed framework primarily focused on the logistics and organization of the assessment because, unlike other large-scale assessments, we have very limited data that were collected specifically for the purpose of measuring the impact of climate change. Any approach needs to be flexible to provide for the vastly different inland fishery issues in highly diverse regions with varying social and economic drivers, coupled with the lack of understanding or reporting of data that may be relevant to the effects of climate change on inland fisheries.

Our recommendation to address a large, complex issue like climate change and inland fisheries is to start small with a focused group before expanding to tackle the entire issue. A suggested framework for developing a very large and complex assessment could include the following aspects:

- Start small, with a team you that you have confidence in;

- Identify your target audience (decision makers? scientists?);

- Incorporate multiple pathways for information (e.g., local fishermen, scientists, indigenous people, fishing communities, managers);

- Use different methods and spatial scales to capture regionally diverse issues and a variety of stakeholders (e.g., long term data, literature review, expert panels) — using one approach may miss critical needs.

Our expert team summarized that fish production is a key issue for global food security, livelihoods, and recreational fishing. More specifically, research quantifying the linkage between climate and production and how fishing communities may cope with changes in fish production caused by climate change is critical (Figure 1). With fishes making up the largest single source of animal protein for humans at a global scale (Béné et al. 2015), understanding the impact of climate change on these systems is of critical importance. Fisheries resources provide different benefits and value to communities depending on geographic location, cultural values, and income generation opportunities. However, there remains a need to understand the benefits of the varied uses to each community to better manage fisheries for sustainable use into the future.

Although our work has highlighted some challenges and different priority research needs (Figure 1) to conduct an assessment of climate change on inland fisheries at a global scale, one positive aspect of this work is that there is a shared vision for fisheries sustainability worldwide, even if the purpose to maintain sustainability may be different. Different regions may focus more on food security (e.g., China, Tanzania, Viet Nam) or biodiversity or recreational fisheries (e.g., U. S.), but all regions identified the need to understand how climate change will affect inland fishes and fisheries. A global assessment of climate change and inland fisheries will, indeed, be very challenging but is vitally necessary. We hope that our initial process and results summarized here can build on existing efforts (e.g., Paukert et al. 2016b) and may help others in the development of a more formal assessment that includes more stakeholders and panel members. Ultimately, we hope that this work will help agencies, NGOs, communities, and other users and regulators of inland fishes and fisheries adapt to a changing climate. 


\section{Acknowledgements}

We thank all the expert panel workshop participants who contributed to this effort, which were all the authors in addition to Doug Austen, Roger Pullin, Paul Simonin, and Dongdavanh Sibounthong. This work was developed through an expert panel workshop hosted and funded by the U.S. Geological Survey National Climate Change and Wildlife Science Center, the Missouri Cooperative Fish and Wildlife Research Unit, and the University of Missouri. The Missouri Cooperative Fish and Wildlife Research Unit is sponsored jointly by the U.S. Geological Survey, Missouri Department of Conservation, University of Missouri, the Wildlife Management Institute, and the U.S. Fish and Wildlife Service. Cooke was supported by the Canada Research Chairs Program, the Too Big to Ignore Network, and NSERC. Chen was supported by Chinese Academy of Sciences (Projects Y45Z04, Y62302) and World Wide Fund for Nature (Project 10002550). The contribution of Cowx was supported under the CERES project funded from the European Union's Horizon 2020 research and innovation programme under grant agreement No 678193.

\section{Conflict of Interest:} none 


\section{References}

Abell R, Thieme ML, Revenga C, et al (2008) Freshwater ecoregions of the world : A new map of biogeo- graphic units for freshwater biodiversity conservation. Bioscience 58:403-414. doi: 10.1641/B580507

Angilletta Jr. MJ (2009) Thermal adaptation: a theoretical and empirical synthesis. Oxford University Press, Oxford, UK

Arlinghaus R, Mehner T, Cowx IG (2002) Reconciling traditional inland fisheries management and sustainability in industrialized countries, with emphasis on Europe. Fish Fish 3:261-316.

Beard TD, Arlinghaus R, Cooke SJ, et al (2011) Ecosystem approach to inland fisheries: research needs and implementation strategies. Biol Lett 7:481-3. doi: 10.1098/rsbl.2011.0046

Beitinger T, Bennett W, McCauley R (2000) Temperature tolerances of North American freshwater fishes exposed to dynamic changes in temperature. Environ Biol Fishes 58:237-275. doi: 10.1023/A:1007676325825

Beitinger TL, Bennett W a (1999) Quantification of the role of accclimation temperature in temperature tolerance of fishes. Environ Biol Fishes 58:277-288.

Bellard C, Bertelsmeier C, Leadley P, et al (2012) Impacts of climate change on the future of biodiversity. Ecol Lett 15:365-377. doi: 10.1111/j.1461-0248.2011.01736.x

Belton B, Thilsted SH (2014) Fisheries in transition: Food and nutrition security implications for the global South. Glob Food Sec 3:59-66. doi: 10.1016/j.gfs.2013.10.001

Béné C, Barange M, Subasinghe R, et al (2015) Feeding 9 billion by 2050 - Putting fish back on the menu. Food Secur 7:261-274. doi: 10.1007/s12571-015-0427-z

Béné C, Neiland A, Jolley T, et al (2003) The Lake Chad Basin. J Asian Afr Stud 38:17-51.

Bonar SA, Mercado-Silva N, Hubert WA, et al (2017) Standard methods for sampling freshwater fishes: opportunities for international collaboration. Fisheries 42:150-156.

Brett JR (1971) Energetic responses of salmon to temperature. A Study of some thermal relations in the physiology and freshwater ecology of Sockeye Salmon (Oncorhynchus nerka). Am Zool 11:99-113. doi: 10.1093/icb/11.1.99

Brett JR, Groves TDD (1979) 6 - Physiological Energetics. In: Fish Physiology. pp 279-352

Brummett RE, Beveridge MCM, Cowx IG (2013) Functional aquatic ecosystems, inland fisheries and the Millennium Development Goals. Fish Fish 14:312-324. doi: 10.1111/j.1467-2979.2012.00470.x

Cheung WWL, Jones MC, Reygondeau G, et al (2016) Structural uncertainty in projecting global fisheries catches under climate change. Ecol Modell 325:57-66. doi: 10.1016/j.ecolmodel.2015.12.018

Cheung WWL, Pauly D, Sarmiento JL (2013) How to make progresss in projecting climate change impacts. ICES J Mar Sci 70:1069-1074. doi: 10.1093/icesjms/fst133

Chen Y, Todd AS, Murphy MH, Lomnicky G (2016) Anticipated water quality changes in response to climate change and potential consequences for inland fishes. Fisheries 41:413-416. doi: $10.1080 / 03632415.2016 .1182509$

Christensen JH, Hewitson B, Busuioc A, et al (2007) Regional climate projections. In: Solomon S, Qin D, Manning M, et al. (eds) Climate change 2007: The physical science basis. Contribution of Working Group I to the Fourth Assessment Report of the Intergovernmental Panel on Climate Change. Cambridge University Press, Cambridge, U.K. and New York, U.S., pp 847-940

Coates D (2002) Inland capture fishery statistics of Southeast Asia: Current status and information needs. Bangkok, Thailand

Cochrane KL, De Young C, Soto D, et al (2009) Climate change implications for fisheries and aquaculture: Overview of current scientific knowledge. Rome, Italy

Comte L, Buisson L, Daufresne M, Grenouillet G (2013) Climate-induced changes in the distribution of freshwater fish: Observed and predicted trends. Freshw Biol 58:625-639. doi: 10.1111/fwb.12081

Comte L, Grenouillet G (2013) Do stream fish track climate change? Assessing distribution shifts in recent decades. Ecography (Cop) 36:1236-1246. doi: 10.1111/j.1600-0587.2013.00282.x

Cooke SJ, Allison EH, Beard TD, et al (2016a) On the sustainability of inland fisheries: Finding a future for the forgotten. Ambio 45:753.

Cooke SJ, Arthington AH, Bonar SA, et al (2016b) Assessment of inland fisheries: A vision for the future. In: Taylor WW, Bartley DM, Goddard CI, et al. (eds) Freshwater, fish, and the future: Proceedings of the Global Cross-Sectoral Conference. American Fisheries Society Press, Bethesda, Maryland, pp 45-62

Cooke SJ, Cowx IG (2004) The role of recreational Ffishing in global fish crises. Bioscience 54:857-859. doi: 10.1641/0006-3568(2004)054[0857:TRORFI]2.0.CO;2

Cooke SJ, Lapointe NWR, Martins EG, et al (2013) Failure to engage the public in issues related to inland fishes 
and fisheries: strategies for building public and political will to promote meaningful conservation. J Fish Biol 83:997-1018. doi: $10.1111 / \mathrm{jfb} .12222$

Coulthard S (2008) Adapting to environmental change in artisanal fisheries-Insights from a South Indian Lagoon. Glob Environ Chang 18:479-489. doi: 10.1016/j.gloenvcha.2008.04.003

Cowx IG, Arlinghaus R, Cooke SJ (2010) Harmonizing recreational fisheries and conservation objectives for aquatic biodiversity in inland waters. J Fish Biol 76:2194-215. doi: 10.1111/j.1095-8649.2010.02686.x

Cowx IG, Portocarrero Aya M (2011) Paradigm shifts in fish conservation: moving to the ecosystem services concept. J Fish Biol 79:1663-80. doi: 10.1111/j.1095-8649.2011.03144.x

Cromier R, Kannen A, Elliott M, et al (2013) Marine and coastal ecoystem-based risk management handbook.

Daly C (2006) Guidelines for assessing the suitability of spatial climate data sets. Int J Climatol 26:707-721. doi: $10.1002 /$ joc. 1322

Darwall W, Smith K, Allen D, et al (2008) Freshwater biodiversity: A hidden resource under threat. Gland, Switzerland

Deutsch CA, Tewksbury JJ, Huey RB, et al (2008) Impacts of climate warming on terrestrial ectotherms across latitude. Proc Natl Acad Sci U S A 105:6668-6672. doi: 10.1073/pnas.0709472105

Donaldson MR, Cooke SJ, Patterson DA, Macdonald JS (2008) Cold shock and fish. J Fish Biol 73:1491-1530. doi: 10.1111/j.1095-8649.2008.02061.x

Dudgeon D, Arthington AH, Gessner MO, et al (2006) Freshwater biodiversity: Importance, threats, status and conservation challenges. Biol Rev 81:163-182. doi: 10.1017/s1464793105006950

Eliason EJ, Clark TD, Hague MJ, et al (2011) Differences in thermal tolerance among sockeye salmon populations. Science (80- ) 1861:109-112.

Elliott JM (1990) The need for long-term investigations in ecology and the contribution of the Freshwater Biological Association. Freshw Biol 23:1-5.

FAO (2014a) CWP Handbook of Fishery Statistical Standards. Section G: Fishing Areas - General. Rome, Italy

FAO (2016) The State of World Fisheries and Aquaculture - 2016 (SOFIA). Rome, Italy

FAO (2014b) The State of World Fisheries and Aquaculture - 2014 (SOFIA). Rome, Italy

FAO (2007) Fishery Country Profile. National Fishery Sector Overview: The United Republic of Tanzania. Rome, Italy

FAO (2010) Report of the FAO Workshop on Climate Change and Fisheries in the African Great Lakes. Bujumbura, Burundi

FAO (2012) Recreational Fisheries. FAO Technical Guidelines for Responsible Fisheries. No. 13. Rome, Italy

Foden WB, Butchart SHM, Stuart SN, et al (2013) Identifying the world's most climate change vulnerable species: A systematic trait-based assessment of all birds, amphibians and corals. PLoS One. doi: 10.1371/journal.pone.0065427

Freire KMF, Machado ML, Crepaldi D (2012) Overview of inland recreational fisheries in Brazil. Fisheries 37:484494. doi: 10.1080/03632415.2012.731867

Freitas V, Cardoso JFMF, Lika K, et al (2010) Temperature tolerance and energetics: a dynamic energy budgetbased comparison of North Atlantic marine species. Philos Trans R Soc B-Biological Sci 365:3553-3565. doi: 10.1098/rstb.2010.0049

Godfray HCJ, Beddinigton JR, Crute IR, et al (2010) Food security: The challenge of feeding 9 billion people. Science (80- ) 327:812-818.

Grimm NB, Chapin FS, Bierwagen B, et al (2013) The impacts of climate change on ecosystem structure and function. Front Ecol Environ 11:474-482. doi: 10.1890/120282

Guo C, Lek S, Ye S, et al (2015) Predicting fish species richness and assemblages with climatic, geographic and morphometric factors: A broad-scale study in Chinese lakes. Limnologica 54:66-74. doi: 10.1016/j.limno.2015.08.002

Gupta N, Bower SD, Raghavan R, et al (2015) Status of recreational fisheries in India: Development, issues, and opportunities. Rev Fish Sci Aquac 23:291-301. doi: 10.1080/23308249.2015.1052366

Halls AS, Johns M (2013) Assessment of the vulnerability of the Mekong Delta Pangasius catfish industry to development and climate change in the Lower Mekong Basin.

Hanson T, Sites D (2015) 2014 U.S. Catfish database. Auburn, Alabama

Heino J, Virkkala R, Toivonen H (2009) Climate change and freshwater biodiversity: Detected patterns, future trends and adaptations in northern regions. Biol Rev 84:39-54. doi: 10.1111/j.1469-185X.2008.00060.x

Huey RB, Kearney MR, Krockenberger A, et al (2012) Predicting organismal vulnerability to climate warming: roles of behaviour, physiology and adaptation. Philos Trans R Soc B-Biological Sci 367:1665-79. doi: 10.1098/rstb.2012.0005 
Hunt LM, Fenichel EP, Fulton DC, et al (2016) Identifying alternate pathways for climate change to impact inland recreational fishers. Fisheries 41:362-372. doi: 10.1080/03632415.2016.1187015

IPCC (2014) Climate Change 2014: Synthesis Report. Geneva, Switzerland

IPCC (2001) Climate Change 2001 Working Group II Report to IPCC AR3. Cambridge University Press, Cambridge, U.K.

Janzen DH (1967) Why mountain passes are higher in the tropics. Am Nat 101:233-249.

Kapetsky JM (2003) Review of the State of World Fishery Resources: Inland Fisheries. Rome

Kiem AS, Hiroshi Ishidaira HPH, Zhou MC, et al (2008) Future hydroclimatology of the Mekong River basin simulated using the high-resolution Japan Meteorological Agency (JMA) AGCM. Hydrol Process 22:13821394. doi: 10.1002/hyp.6947

Kitchell JF, Stewart DJ, Weininger D (1977) Applications of a Bioenergetics Model to Yellow Perch (Perca flavescens) and Walleye (Stizostedion vitreum vitreum). J Fish Res Board Canada 34:1922-1935.

Kovach RP, Muhlfeld CC, Al-Chokhachy R, et al (2016) Impacts of climatic variation on trout: A global synthesis and path forward. Rev Fish Biol Fish 26:135-151. doi: 10.1007/s11160-015-9414-x

Krabbenhoft TJ, Platania SP, Turner TF (2014) Interannual variation in reproductive phenology in a riverine fish assemblage: Implications for predicting the effects of climate change and altered flow regimes. Freshw Biol 59:1744-1754. doi: 10.1111/fwb.12379

Lobell DB, Burke MB, Tebaldi C, et al (2008) Prioritizing climate change adaptation needs for food security in 2030. Science (80) 319:607-610.

Logez M, Bady P, Melcher A et al. (2013), A continental-scale analysis of fish assemblage functional structure in European rivers. Ecography 36: 80-91. doi:10.1111/j.1600-0587.2012.07447.x

Lynch AJ, Cooke SJ, Deines AM, et al (2016a) The social, economic, and environmental importance of inland fishes and fisheries. Environ Rev 24:1-7. doi: 10.1139/er-2015-0064

Lynch AJ, Myers BJE, Chu C, et al (2016b) Climate change effects on North American inland fish populations and assemblages. Fisheries 41:346-361. doi: 10.1080/03632415.2016.1186016

Maass M, Equihua M (2015) Earth stewardship, socioecosystems, the need for a transdisciplinary approach and the role of the international long term ecological research network (ILTER). In: Rozzi R, Chapin FSI, Callicott JB, et al. (eds) Earth stewardship: Linking ecology and ethics in theory and practice. Springer, Heidelberg, Germany, pp 217-233

Maberly SC, Elliott JA (2012) Insights from long-term studies in the Windermere catchment: External stressors, internal interactions and the structure and function of lake ecosystems. Freshw Biol 57:233-243. doi: $10.1111 / \mathrm{j} .1365-2427.2011 .02718 . \mathrm{x}$

MacIntyre S (2012) Climatic variability, mixing dynamics, and ecological consequences in the African Great Lakes. Clim Chang Glob Warm Inl Waters Impacts Mitig Ecosyst Soc 311-336. doi: 10.1002/9781118470596.ch18

Martin BT, Zimmer EI, Grimm V, Jager T (2012) Dynamic energy Bbdget theory meets individual-based modelling: A generic and accessible implementation. Methods Ecol Evol 3:445-449. doi: 10.1111/j.2041210X.2011.00168.X

Marx A (2015) The State of Food Insecurity in the World: Meeting the 2015 international hunger targets: taking stock of uneven progress.

Mehner T, Brucet S, Argillier C, et al (2017) Metadata of European Lake Fishes Dataset. Freshw Metadata J 1-8. doi: $10.15504 / \mathrm{fmj} .2017 .23$

Midway SR, Wagner T, Zydlewski JD, et al (2016) Transboundary fisheries science: Meeting the challenges of inland fisheries. 41:536-546. doi: 10.1080/03632415.2016.1208090

MOA (Ministry of Agriculture) (2015) China Fishery Statistical Yearbook. Beijing, China

Moore CM and J, Minns CK, Moore JE (1995) Factors limiting the distributions of Ontario's freshwater fishes: the role of climate and other variables, and the potential impacts of climate change. In: Beamish RJ (ed) Climate change and northern fish populations. National Research Council of Canada, Ottawa, ON, pp 137-160

Muhlfeld CC, Kovach RP, Jones LA, et al (2014) Invasive hybridization in a threatened species is accelerated by climate change. Nat Clim Chang 4:620-624. doi: 10.1038/NCLIMATE2252

Nam S, Phommakone S, Vuthy L, et al. (2015) Lower Mekong fisheries estimated to be worth around \$17 billion a year. Catch and Cultre: Fisheries Research and Development in the Mekong Region 21(3):4-7.

Newton JR, Smith-Keune C, Jerry DR (2010) Thermal tolerance varies in tropical and sub-tropical populations of barramundi (Lates calcarifer) consistent with local adaptation. Aquaculture 308:S128-S132. doi: 10.1016/j.aquaculture.2010.05.040

Ney JJ (1993) Bioenergetics modeling today: Growing pains on the cutting edge. Trans Am Fish Soc 122:736-748. doi: $10.1577 / 1548-8659(1993) 122<0736$ 
Norin T, Malte H, Clark TD (2016) Differential plasticity of metabolic rate phenotypes in a tropical fish facing environmental change. Funct Ecol 30:369-378. doi: 10.1111/1365-2435.12503

Noyes PD, McElwee MK, Miller HD, et al (2009) The toxicology of climate change: Environmental contaminants in a warming world. Environ Int 35:971-986. doi: 10.1016/j.envint.2009.02.006

Paukert C, Glazer B, Hansen GJA, et al (2016a) Adapting fisheries management to a changing climate. Fisheries 41:374-384. doi: 10.1080/03632415.2016.1185009

Paukert CP, Lynch AJ, Whitney JE (2016b) Effects of climate change on North American inland fishes: Introduction to the special issue. Fisheries 41:329-330. doi: 10.1080/03632415.2016.1187011

Peck LS, Clark MS, Morley SA, et al (2009) Animal temperature limits and ecological relevance: Effects of size, activity and rates of change. Funct Ecol 23:248-256. doi: 10.1111/j.1365-2435.2008.01537.x

Petersen JH, Paukert CP (2005) Development of a Bioenergetics Model for Humpback Chub and Evaluation of Water Temperature Changes in the Grand Canyon, Colorado River. Trans Am Fish Soc 134:960-974. doi: 10.1577/T04-090.1

Pörtner HO, Farrell AP (2008) Physiology and climate change. Science (80- ) 322:690-693.

Pörtner HO, Peck MA (2010) Climate change effects on fishes and fisheries: towards a cause-and-effect understanding. J Fish Biol 77:1745-79. doi: 10.1111/j.1095-8649.2010.02783.x

Rice JA, Cochran PA (1984) Independent evaluation of a bioenergetics model for largemouth bass. Ecology 65:732739. doi: $10.2307 / 1938045$

Rijnsdorp AD, Peck MA, Engelhard GH, et al (2009) Resolving the effect of climate change on fish populations. ICES J Mar Sci 66:000-000.

Roessig JM, Woodley CM, Cech JJ, Hansen LJ (2004) Effects of global climate change on marine and estuarine fishes and fisheries. Rev Fish Biol Fish 14:251-275. doi: 10.1007/s11160-004-6749-0

Schmidhuber J, Tubiello FN (2007) Global food security under climate change. Proc Natl Acad Sci U S A 104:19703-19708. doi: 10.1073/pnas.0701976104

Sievert NA, Paukert CP, Tsang YP, Infante D (2016) Development and assessment of indices to determine stream fish vulnerability to climate change and habitat alteration. Ecol Indic 67:403-416. doi: 10.1016/j.ecolind.2016.03.013

Smith LED, Khoa SN, Lorenzen K (2005) Livelihood functions of inland fisheries: policy implications in developing countries. Water Policy 7:359-383.

Staudt A, Leidner AK, Howard J, et al (2013) The added complications of climate change: understanding and managing biodiversity and ecosystems. Front Ecol Environ 11:494-501.

Stillman JH (2003) Acclimation capacity underlies susceptibility to climate change. Science (80- ) 301:65. doi: $10.1126 /$ science. 1083073

Terblanche JS, Deere JA, Clusella-Trullas S, et al (2007) Critical thermal limits depend on methodological context. Philos Trans R Soc B-Biological Sci 274:2935-42. doi: 10.1098/rspb.2007.0985

Terblanche JS, Hoffmann AA, Mitchell KA, et al (2011) Ecologically relevant measures of tolerance to potentially lethal temperatures. J Exp Biol 214:3713-3725. doi: 10.1242/jeb.061283

Tytler P, Calow P (1985) Fish energetics. Croom Helm, London, UK

UN (United Nations) (2016) The Sustainable Development Goals Report. New York, N.Y.

Urban MC, Tewksbury JJ, Sheldon KS (2012) On a collision course: Competition and dispersal differences create no-analogue communities and cause extinctions during climate change. Proc R Soc B Biol Sci 279:20722080. doi: $10.1098 / \mathrm{rspb} .2011 .2367$

USFWS - USCB (U.S. Fish \& Wildlife Service and U.S. Census Bureau) (2011) 2011 National Survey of Fishing, Hunting, and Wildlife-Associated Recreation. Washington, D.C.

Wang L, Infante D, Riseng C, Wehrly K (2016) Geostatistics: An overview advancement of geospatial capability by NRiSD and GLAHF in enhancing aquatic ecosystem research and management.

Ward EJ, Anderson JH, Beechie TJ, et al (2015) Increasing hydrologic variability threatens depleted anadromous fish populations. Glob Chang Biol 21:2500-2509. doi: 10.1111/gcb.12847

Welcomme RL, Cowx IG, Coates D, et al (2010) Inland capture fisheries. Philos Trans R Soc B-Biological Sci 365:2881-96. doi: 10.1098/rstb.2010.0168

Westhoff JT, Paukert CP (2014) Climate change simulations predict altered biotic response in a thermally heterogeneous stream system. PLoS One 9:1-15. doi: 10.1371/journal.pone.0111438

Whitney JE, Al-Chokhachy R, Bunnell DB, et al (2016) Physiological basis of climate change impacts on North American inland fishes. Fisheries 41:332-345. doi: 10.1080/03632415.2016.1186656

Whittier J, Sievert N, Loftus A, et al (2016) Leveraging BIG Data from BIG Databases to answer big question. Fisheries 41:417-419. doi: 10.1080/03632415.2016.1191911 
Wiens JA, Bachelet D (2010) Matching the multiple scales of conservation with the multiple scales of climate change: Special section. Conserv Biol 24:51-62. doi: 10.1111/j.1523-1739.2009.01409.x

Wikelski M, Cooke SJ (2006) Conservation physiology. Trends Ecol Evol 21:38-46. doi: $10.1016 / j$.tree.2005.10.018

Wilder M, Nguyen TP (2002) The status of aquaculture in the Mekong Delta Region of Vietnam: Sustainable production and combined farming systems. Fish Sci 68:847-850.

Williams M (1996) The transition in the contribution of living aquatic resources to food security. Washington, D.C. Yang Z, Chen Y, Yu R, et al (2016) Responsible recreational fisheries: A Chinese perspective. Fisheries XX:XX$\mathrm{XX}$.

Youn S-J, Taylor WW, Lynch AJ, et al (2014) Inland capture fishery contributions to global food security and threats to their future. Glob Food Sec 3:142-148. doi: 10.1016/j.gfs.2014.09.005

Yu H (ed) (2009) Recreational Fisheries. Northeast Forestry University Press, Harbin, China 
860 Table 1. The range of provisioning, regulating, supporting and cultural services provided by functional aquatic

861

862 ecosystems (after Brummett et al. 2013). Different aquatic ecosystems will provide some or all of these.

\begin{tabular}{ll}
\hline Ecosystem service & Examples \\
\hline Cultural & $\begin{array}{l}\text { Scientific discovery, spiritual, ceremonial, recreation (including } \\
\text { ecotourism), aesthetic }\end{array}$ \\
Provisioning & $\begin{array}{l}\text { Foods, fisheries, crops, water, construction materials, medicines, } \\
\text { clothing materials, hydropower and biomass fuels }\end{array}$ \\
Regulating & Climate, floods, carbon sequestration, nutrient balance, water filtration \\
Supporting & Nutrient cycling, photosynthesis, soil formation \\
\hline
\end{tabular}

863

864 


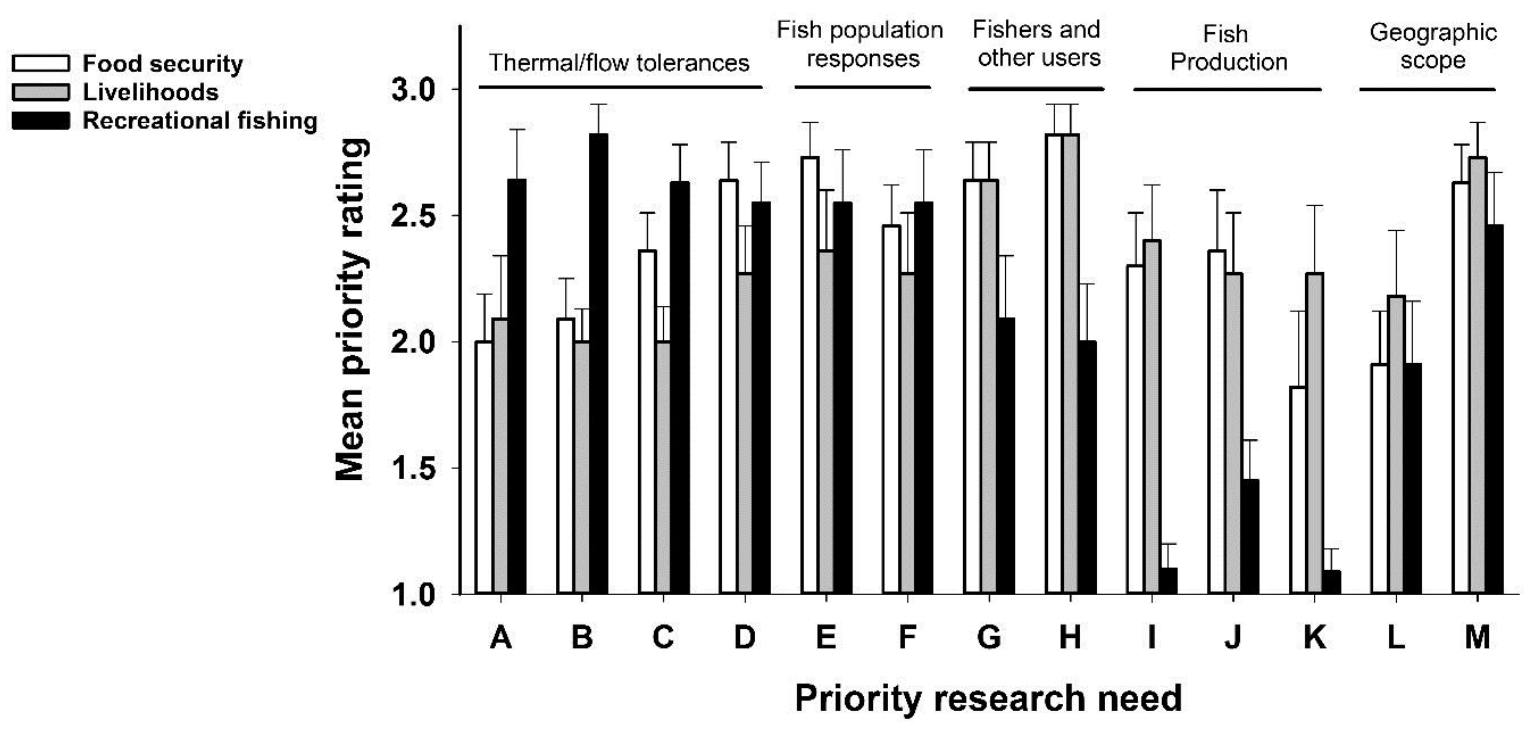

867 Fig. 1. Mean rating (1=low, $2=$ medium, $3=$ high) of priority research needs by theme for a global assessment on the effects of climate change on inland fishes developed from an expert panel workshop (see text). Errors bars represent one standard error. Priority needs are A) Maximum thermal tolerance, B) Response to dynamic temperature (not just maximum), C) Response to hydrologic changes, D) Adaptive capacity to respond to changes in temperature and flow, E) Understand fish population size so change caused by climate can be measured, F) Individual fish and population-level responses to climate change (e.g., growth), G) Response of users to drought and extreme events, H) Understand how fishing communities may cope with changes in fish production, I) Quantifying the linkages of aquaculture production to floods in floodplain areas, J) Understand the influence of saltwater intrusion of fish communities/production, K) Developing successful production systems in areas of high saltwater intrusion, L) Link between catch, temperature, and hydrology in different systems/regions, and MK) Better geographic representation of all studies. 